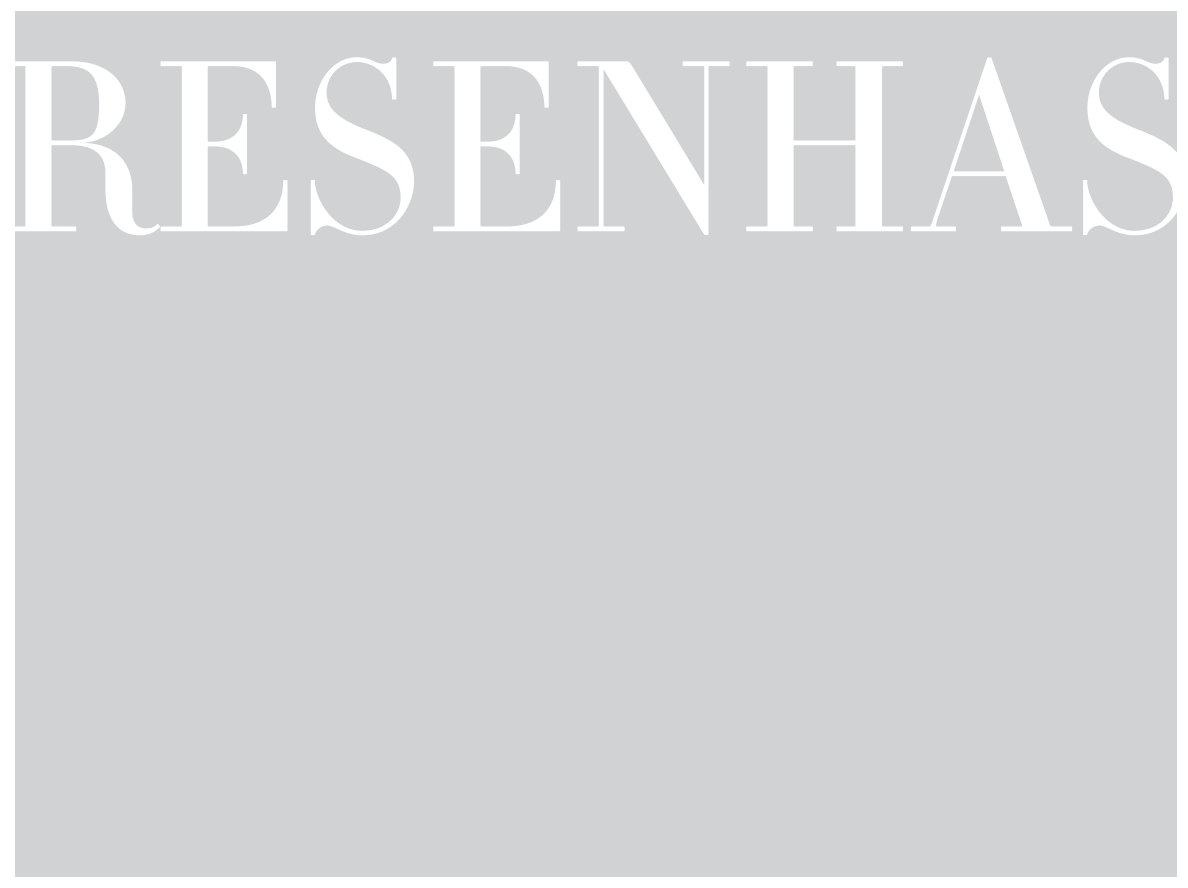

\title{
A EDUCAÇÃO ESPONTÂNEA: QUANDO OS ADOLESCENTES SE FORMAM POR SI PRÓPRIOS
}

ANNE BARRĖRE

[L'Éducation buissonnière: quand les adolescents se forment par euxmêmes]

PARIS: ARMAND COLIN, 2011. 228 P.

Embora alunos, crianças e adolescentes ainda conseguem ter o seu próprio tempo, em que desenvolvem atividades da sua escolha. São atividades como esportes e outras formas de lazer organizado; inserção em atividades da cultura de massa; uso de tecnologias para fins relacionais; a convivência com colegas e outras atividades que Barrère comparou às "provas" rituais da Paideia grega, que formavam o caráter (neste caso, para o "bem" socialmente definido). Caberia acrescentar outras "provas”, como a separação dos pais e as recomposições familiares, além dos ordálios cada vez mais temíveis do ingresso no trabalho. Com efeito, essa socióloga, a partir do contato com os filhos e seus amigos adolescentes, desenvolveu sofisticada pesquisa qualitativa sobre a autoformação desse grupo etário e sociocultural.

Verificamos, mais uma vez, que, para ser aluno, é preciso dominar o currículo da sala de aula, ao passo que, para ser adolescente e jovem, cabe transitar pelos meandros dos currículos da rua, que podem irradiar-se pelos pátios e arredores escolares, onde se exercitam as sociabilidades e protagonismos adolescentes e até infantis. As provas e ritos integradores se desenvolvem tanto na escola, em particular por meio das avaliações (cognitivas, afetivas, sociais, morais), para o papel de aluno, e, fora dela e da família, para o papel de jovem. Os currículos 
da rua são complexos: é preciso saber habitar a pele de uma multiplicidade de outros; captar, interpretar, satisfazer e contrariar expectativas de comportamento; usar diversas máscaras, sem confundir nenhuma delas com o próprio rosto; ser sem parecer e parecer sem ser; mostrar ou ocultar tristezas e alegrias, realizações e frustrações; liderar e ser liderado; concordar e discordar; negociar entre autonomia e heteronomia, tanto a da família quanto a dos grupos de pertencimento; estabelecer limites para a sua autonomia e os status nos grupos; nadar conforme as correntes, escapando sutilmente para as margens em determinadas circunstâncias; ser confiável, mantendo fidelidade aos códigos grupais; participar de certos gostos e padrões de consumo; apresentar certas aparências, conforme o tempo e o espaço; demonstrar autonomia e desenvolver outras características que, inegavelmente, formam o caráter, construindo e misturando os paradoxos pós-modernos com a dualidade dos antigos em meio a uma tragédia grega encenada com máscaras.

Certos educadores superestimam as relações antípodas entre as culturas escolares e adolescentes. Umas não são o avesso das outras, mas a tensão é maior para os alunos socialmente menos aquinhoados, distantes do capital cultural. Essa oposição e os consequentes tédio e revolta contra a escola não são exclusividade deles. Culturas adolescentes e juvenis também não conduzem necessariamente a comportamentos antissociais, ainda que o teste de limites, a transgressão "lúdica”, o ingresso nas terras de aventuras e a aceitação de desafios sejam riscos. Porém, de fato, certas culturas etárias podem ser enredadas tanto pelo crime organizado global, como por diferentes tipos de cultura de massa.

Embora mantendo o monopólio das credenciais, a escola e, em grande parte, a família perderam o monopólio dos conhecimentos e da formação do caráter. Por isso mesmo, Barrère distinguiu cinco provas, similarmente à Paideia. A primeira é a da adesão ao amplo leque de atividades à escolha dos adolescentes. Necessárias à descompressão do tempo escolar e do seu tentáculo doméstico, o dever de casa, as atividades eletivas, por atraentes, levam a uma agenda sobrecarregada. Desse modo, é preciso aprender a gerir o tempo e os custos, como também o grau de dedicação a cada uma delas. Há tempo de singularizar e pluralizar, de concentrar e dispersar, sendo a conquista do autodomínio o desfecho feliz. Nesse sentido, o grupo de colegas é um agente ativo de regulação e, ao mesmo tempo, de apelo a excessos, tateando em busca de limites.

A segunda prova é a da busca de experiências vividas intensamente, que implicam saber aproximar-se e afastar-se ou, mais uma vez, estabelecer limites. Viver plenamente a vida, o delírio, o fascínio e a paixão, é necessário para romper o tédio e a rotina, afirmando a vida e assumindo plenamente a subjetividade e a condição juvenil, como é culturalmente definida. Ao mesmo tempo porém, é preciso aprender a conjugar intensidade e duração das atividades, bem como a evitar as derrapagens das 
condutas de risco. A escola é lenta, a música e a dança são intensas e dinâmicas, elevam ao êxtase, embora exista o reverso profundo da depressão e do suicídio, deixando os alunos a viver entre Apolo e Dionísio. Da mesma forma que os adolescentes fazem o zapping das atividades, também desenvolvem a sua bolha individual. Como na escola, sucessos mais frequentes que fracassos são fatores de adesão e de abandono de atividades eletivas.

A terceira prova é a da singularidade, ou seja, tornar-se indivíduo, pessoa. O pesado manto da uniformização se faz efetivo tanto pela cultura de massa quanto pelo conformismo grupal, se bem que os processos não são monolíticos. Ao contrário, existe uma sutil dialética entre a padronização e a individualização quando os olhos captam os pormenores. A coerção social cede lugar à necessidade de construir uma personalidade nascente, um sujeito dentro e pelo grupo. Contrapõem-se e se associam desejo de pertencimento e afirmação pessoal, integração ao grupo e subjetivação, comportamentos uniformes e pequenas diferenças de apresentação pessoal, pensamentos e gostos, que constroem a singularização. Claro que há grupos mais ou menos abertos às diferenças, todavia o conformismo total se revela impossível, inclusive porque agir como os outros não evita as críticas. Por outro lado, as normas e padrões grupais são dinâmicos, de modo que é preciso efetuar escolhas.

A quarta e última prova é a de caminhar na dimensão temporal, isto é, de estabelecer os elos entre o presente e o futuro, entre as atividades da adolescência e as projeções da idade adulta. Em vez do imediatismo, favorecido pelo consumo e, ao mesmo tempo, criticado e praticado pelos adultos, é preciso olhar adiante. O adolescente mira o futuro com a ótica do sonho, influenciado pelas mitologias da mídia. Os sonhos não apenas mudam, como se envolvem na névoa indefinida de inviáveis ambições. Entretanto, para converter sonhos em projetos, é preciso um caminho. Este processo de escolhas viáveis, exigido pela escola e pela família, implica não raro a morte do sonho e a superação do respectivo luto. Envolve o planejamento de pequenos e gradativos passos, consistentes, reunindo recursos e superando obstáculos. Essa prova decisiva da vida adulta se entrecruza com as anteriores: é um convite exigente para superar a polarização de uma atividade, mais intensa que duradoura, que, ao mesmo tempo, permite conquistar a singularidade, uma vez que o projeto de futuro é pessoal. O atendimento a essa convocação mobiliza o recurso ao capital social e cultural, muitas vezes a uma modalidade de transmissão ocupacional familiar, inclusive porque o sucesso escolar se torna cada vez menos suficiente.

Já os adolescentes e jovens dos meios populares utilizam outra lógica de inserção, baseada em novas articulações entre sonho, projeto e realidade, que, em grande parte, escapam à órbita da escola e da família. Para as duas populações, mas sobretudo para a menos aquinhoada, 
a experimentação de alternativas por ensaio e erro tem papel relevante. No entanto, a autora hipotetiza que, com a inflação escolar e o afrouxamento dos laços entre os diplomas e a alocação social dos indivíduos, a escola pode perder importância no futuro. Em contraponto, a prova de caráter do caminhar poderá ter maior pertinência nos próximos anos. Ou, pelo menos, em tempos de crise, traçar o caminho estará mais longe dos sonhos e projetos adolescentes.

As conclusões apontam para certa miopia do pessimismo que caracteriza muitas opiniões de educadores e da sociedade. Nas atividades eletivas os adolescentes participantes da pesquisa enfrentam as provas com lucidez e equilíbrio, se superam, buscam a singularização emancipadora, educam-se numa área livre dos discursos escolares, que, a nosso ver, incluem mais valores proclamados que vividos. A visão da escola para muitos é a de um castelo sitiado pela cultura de massa e pela tirania dos pares, mas também cabe relativizar conclusões de que é impossível educar diante da cultura de massa, em concorrência "cruel" com a cultura escolar. Consideremos, porém, que as coisas são menos simples para os que não contam com o capital cultural para vencer as provas da Paideia. Os meios populares desenvolvem culturas ou subculturas que parecem necessárias à sobrevivência dos que os habitam.

A autora ainda discute a visão da escola sob o prisma das atividades eletivas. Do ponto de vista da socialização, tais atividades também socializam e apresentam certa convergência em face dos valores da escola. Esta última se expande no que ela chama de "pedagogização da sociedade”, com tempos, espaços e rituais fixos, muitas (a nosso ver, não todas) atividades eletivas apresentam um currículo assistemático, alternativo e até certo ponto lúdico, que envolve a introdução em conhecimentos e habilidades, além de aperfeiçoamento e obtenção de resultados, inclusive em competições públicas. Não raro os adolescentes encontram instrutores tão duros que os educadores considerariam inaceitáveis nas escolas. É arriscado supervalorizar tal currículo, contudo cabe lembrar que as pessoas desenvolvem aprendizagens e competências não reconhecidas pela escola, que poderiam ter lugar nela e que hoje, ao menos na área profissional, muitos países requerem a sua certificação, pela própria escola, já que ela mantém o monopólio das credenciais (seria um caso em que se nomeia Drácula gestor do banco de sangue?).

Daí brota outra questão. O currículo das atividades eletivas inclui imagens, música, informática e práticas esportivas, num ritmo dinâmico, alheio à cultura escolar. Há anos uma educadora manifestou a sua perplexidade ante o tédio manifestado pelos adolescentes nas pasteurizadas aulas de educação física, em contraste com a sua devoção aos exercícios nas academias. Contrastava o clima morno das aulas de línguas estrangeiras, com o interesse e a efetividade das aulas de "cursos livres", integrantes do tal sistema educacional "sombra”. Acrescen- 
taríamos os resultados concretos das aulas de apoio ou de explicadores hábeis no aproveitamento dos alunos, em contraste com as "aulas de recuperação” que até hoje muitas escolas inserem no calendário letivo e que parecem ser úteis apenas para cumprir a letra da lei (diria Anísio, citado por Darcy: Tudo legal e tudo muito ruim).

Por fim, Barrère situa a necessidade de refletir sobre a educação escolar a partir das atividades eletivas. A formação (do caráter) depende menos da escola que as expectativas usuais. Diante da pressão escolar, os participantes da pesquisa buscaram fora da escola a construção pessoal e a descompressão do tempo escolar. A escola foi retratada com um déficit de intensidade e dinamismo, daí o aborrecimento ou o tédio. No código popular: a escola poderia ser menos “chata”?

A escola republicana, ideal da modernidade, inseria-se num projeto político destinado a modelar as novas gerações. Então, indaga a autora, a serviço de que projeto está o rompimento entre a cultura escolar tradicional e as novas formas culturais? Tanto o pânico moral dos adultos em relação aos jovens quanto as atividades eletivas são antigos. De igual modo, criticar o anacronismo das instituições, entre elas a escola, não é novidade. O inédito, constatado pela pesquisa, é o estratagema que leva os adolescentes a provar a sua força de caráter, ideais e sua singularidade em grande parte fora das instituições tradicionais, como a escola. É claro que, no ensaio e erro, ocorrem excessos, adições e dificuldades de encontrar os caminhos e limites, mas o que chama a atenção de Barrère é a capacidade de alguns no sentido de fazer de certas atividades eletivas "verdadeiras tutoras da sua construção pessoal” (p. 207).

Da mesma forma que as flores da primavera desafiam as pedras e o cimento, irrompendo sem licença nos seus interstícios, parece-nos que os adolescentes não se saem tão mal como esperam os pessimistas, nem tão bem como supõem os otimistas. No seio das contradições da sociedade, das angústias e mudanças inesperadas, a capacidade de superação e flexibilização não podem ser subestimadas. Como denominador comum, entre ambos os extremos, fica a conclusão de que os desafios para a escola parecem crescer. Há que definir o que é educação e o que cabe à escola, tão reduzida a conteúdos, testes e diplomas.

A História mostra que os monopólios têm a trajetória de estrelas cadentes. Eles por si sós dificilmente poderão manter-se nesta modernidade caracterizada pela instabilidade estável e a efemeridade do eterno fluxo, conforme Heráclito. A pesquisa de Barrère descerra a delicada tessitura dos interesses do alunado e da incoerência entre estes e os currículos escolares, construídos por adultos numa arena de interesses também adultos, onde se hierarquizam prioridades. Não propomos o populismo educacional, pelo qual a juventude decida o que estudar na escola. É fato, porém, que se torna evidente sua alienação, inclusive dos "herdeiros". 
Ao distanciar o foco acadêmico das necessidades e interesses discentes, a escola corre o risco de tornar-se um quisto cultural. Já no início do século XX, Dewey e outros filósofos propunham soluções para a educação escolar ante as mudanças da sociedade urbano-industrial e a construção histórico-social da juventude e da adolescência, cuja identidade se delineava como tímido ensaio. Por isso, entre outros caminhos (agora para os educadores), é preciso estudar e incentivar o engajamento dos alunos na escola, e poder pensar nesse ambiente como a ágora, local de prática da cidadania, construção e troca de conhecimento das mais diversas áreas na polis. Sem a vontade do aluno, que surge, no âmago de cada um, ao mesmo tempo como fator e efeito da dinâmica social, não se efetivam o processo educativo ou a aprendizagem.

DIOGO ACIOLI LIMA

aciolidiogo@gmail.com

IVAR CÉSAR OLIVEIRA DE VASCONCELOS

ivcov@hotmail.com

CANDIDO ALBERTO GOMES

clgomes@terra.com.br

Pesquisadores da Cátedra Unesco de Juventude, Educação e Sociedade da Universidade Católica de Brasília

\section{HISTÓRIAS ÍNTIMAS: SEXUALIDADE E EROTISMO NA HISTÓRIA DO BRASIL}

MARY DEL PRIORE

SÃO PAULO: PLANETA, 2011. 254 P.

É quase desnecessário afirmar que uma discussão sobre sexualidade, erotismo e pudor não pode prescindir de um debate sobre relações de gênero. É desse assunto que trata Mary del Priore em seu novo livro, Histórias íntimas: sexualidade e erotismo na história do Brasil. Novamente, a prestigiada historiadora carioca brinda-nos com um tema, no mínimo curioso, cujo conteúdo é antecedido por um prefácio escrito pelo saudoso Moacyr Scliar.

Se o título do livro aguça o nosso interesse pelo seu conteúdo, a sua capa não nos menos instiga. Nela, a imagem de uma enorme abertura de fechadura nos leva a uma série de impressões: a quebra da privacidade por um curioso que, por aquele orifício, observa pessoas em situações de intimidade; o desejo feminino aprisionado por um cinto de castidade posto por um marido cioso em cuidar de sua honra; uma metáfora da genitália feminina, uma fenda que, segundo os pregadores barrocos, era “porta do inferno e entrada do Diabo" (2011, p. 32). 